\title{
A comparative study between single layer versus double layer closure in ileostomy reversal
}

\author{
Sushil Mittal ${ }^{1}$, Harnam Singh ${ }^{2}$, Gurpreet Singh ${ }^{3}$, Anand Munghate ${ }^{3}$, Anjna Garg ${ }^{4}$, Manish Yadav ${ }^{3}$ \\ ${ }^{1}$ Associate Professor, Department of Surgery, Government Medical College, Patiala, India, ${ }^{2}$ Assistant Professor, Department of Surgery, \\ Government Medical College, Patiala, India, ${ }^{3}$ Junior Resident, Department of Surgery, Government Medical College, Patiala, India, ${ }^{4}$ Senior \\ Resident, Department of Surgery, Government Medical College, Patiala, India
}

\section{A B S T R A C T}

Background: Ileal perforation peritonitis is a common surgical emergency in the Indian subcontinent and in tropical countries. Formation of an intestinal stoma is frequently a component of surgical intervention for diseases of the small bowel. The technique for stoma reversal has remained controversial is the use of either one or two layers of sutures for anastomosis. Methods: Sixty patients with ileostomy were taken for study. These patients divided in two groups $A$ and $B, 30$ each. These patients were taken up for ileostomy closure in single layer (group A) (n-30) \& double layer (group B) (n-30). Results: 60 Patients of ileostomy were studied, divided equally in 2 groups, A decreased intra operative time was seen in Group A when compared with Group B with no any significant comparative complication in these groups. Conclusion: Two-layer anastomosis for ileostomy closure offers no definite advantage over single layer anastomosis in terms of postoperative leak and other complications. Single layer ileostomy closure technique is safe, easy to perform and simply to taught. Considering duration of the anastomosis procedure and medical expenses single-layer intestinal anastomosis may prove the choice of procedure for most of the surgeons.

Key words: lleostomy closure, Acute abdomen, Peritonitis, Anastomosis, Stoma reversal
Access this article online Website:

http://nepjol.info/index.php/AJMS

DOI: $10.3126 / a j m s . v 6 \mathrm{i} 2.10080$

\section{INTRODUCTION}

Formation of an intestinal stoma is frequently a component of surgical intervention for diseases of the small bowel and colorectal pathology. The most common intestinal stomas are ileostomies and colostomies; either end or loop stomas. It is understandable that person with stoma want their bowel continuity restored as early as possible. Ideal time to do so is at least 9-12 weeks after the surgery so that the time interval allows the adhesions to settle down, the patient to recover from previous operation and any swelling within the abdomen and the stoma site to fully resolve. ${ }^{1}$

Controversy regarding single versus double layer anastomosis (stoma reversal) goes as back as 1887 when Halsted proposed interrupted extra mucosal suturing. By 1931, more than 52 techniques for G.I anastomosis had been described. ${ }^{2}$
Different techniques of intestinal anastomosis are

1. Conventional methods, (A) Sutured Single-layer (interrupted or continuous) and Two-layered, (B) Stapled

2. Unconventional methods, (A) Compression rings-Biodegradable anastomosis ring-BAR ('Valtrac') and-Non-degradable (AKA2), (B) Tissue glue and (C) Laser welding

The basic principles of the intestinal suture were established more than 100 years ago by Travers, Lambert and Halsted. ${ }^{3}$ Two-layer anastomosis was done by Larry in the $19^{\text {th }}$ century. ${ }^{4}$ In two-layer anastomosis a running absorbable suture for a transmural inner layer and interrupted silk sutures for an outer inverted seromuscular layer has been standard for most surgical situations. The single-layer continuous anastomosis is a contemporary innovation first 
described by Hautefeuille in $1976 .{ }^{5}$ In the USA, the first mention of this technique was by Allen et al. ${ }^{6}$

Many surgeons probably now use single-layer suturing due to reduction in ischemia, tissue necrosis, or narrowing of the lumen compared to the two-layer methods. The aim of the present study is to evaluate the outcome of single layer versus double layer ileostomy closure in terms of operative and post operative outcome in each group like time taken for surgery, cost factor, wound infection, intraabdominal abscess, stricture of anastomosis site, anastomotic leak, peritonitis, septicemia and death. The study will help to establish the criteria for instituting the management modality and the outcome of these procedures. Effective management of the disease will help in decreasing morbidity and mortality associated with the procedure.

\section{METHODS}

This comparative study was conducted over a period of 18 months from January 2012 to June 2013 in the Department of General Surgery, Govt. Medical College \& Rajindra Hospital Patiala. Sixty patients with ileostomy were taken for study. These patients were divided in two groups A and B, each group was of thirty patients. The ileostomy closure wase done in single layer (group A) (n-30) \& double layer (group B) (n-30), comparative study was done between both the procedures. All cases were performed by experienced surgeons. In single layer group, ileostomy closure was carried out in interrupted method with seromuscular non absorbable silk 3-0 suture. In double layer ileostomy closure was carried out by inner layer with continuous absorbable 3-0 polyglactin 910 suture and external layer with interrupted 3-0 silk suture. Operative and post operative outcome wound infection, intraabdominal abscess, stricture of anastomosis site, anastomotic leak, peritonitis, septicemia and time taken for surgery, cost factor, wound infection, intra abdominal abscess and death were evaluated for wound infection, intra abdominal abscess and stricture of anastomosis site. All ileostomy closures were carried out with hand sewn method.

\section{RESULTS}

During this 18 months period of study ileal perforations were most commonly observed in third and fourth decade of life which lead to stoma formation. Ileostomy closure done more commonly in males with ratio 6.5 (Male:Female:6.5:1) with the mean age for ileostomy closure in both procdure was 36.12 years with range from 15-70 years (Table 1). The mean operation time for ileostomy closure from starting of first stitch to last stitch in single layer Group A was 15.3 minute ranging from 8-22 min and in double layer ileostomy closure Group B was 24.2 min ranging from 16-36 min (Table 2).

The average duration of hospital stay of the patients in Group A was 12.8 days and in Group B was 11.7 days. In Group A wound infection was most common complication $5(16.67 \%)$ followed by abdominal collection $3(10.00 \%)$, wound dehiscence and systemic complication $2(6.67 \%)$ each. In Group B wound infection was most common complication 7 (23.33\%) followed by wound dehiscence $3(10.00 \%)$, abdominal collection and systemic complication $2(6.67 \%)$ each and intestinal obstruction in $1(3.33 \%)$. Anastomotic leak occur in $2(6.67 \%)$ patients in each Group in our study requiring reoperation (Figure 1).

\section{DISCUSSION}

Anastomotic failure had always been a cause for concern in patients undergoing surgery with gastrointestinal anastomosis, as it adversely affects the surgical outcome. Healing process is dependent on general factors as age, state of nutrition and cocxistion disease like renal failure, jaundice, malignancy, as well as local factors like vascularity, sepsis and suture technique. ${ }^{7}$

\begin{tabular}{lccccc}
\multicolumn{3}{l}{ Table 1: Age distribution in the study } \\
\hline $\begin{array}{lccccc}\text { Age group } \\
\text { (in years) }\end{array}$ & \multicolumn{2}{c}{ Group A } & & \multicolumn{2}{c}{ Group B } \\
\cline { 2 - 3 } \cline { 5 - 6 } \cline { 5 - 6 } $10-20$ & 3 & 10 & & 4 & 13.33 \\
$21-30$ & 7 & 23.34 & & 8 & 26.67 \\
$31-40$ & 10 & 33.33 & & 9 & 30.00 \\
$41-50$ & 4 & 13.33 & & 5 & 16.67 \\
$51-60$ & 4 & 13.33 & & 4 & 13.33 \\
$61-70$ & 2 & 6.67 & & 0 & 0 \\
Total & 30 & 100 & & 30 & 100 \\
Range & $15-70$ & \multicolumn{3}{c}{$15-60$} \\
Mean $\pm S D$ & $37.07 \pm 13.21$ & & $35.16 \pm 11.95$ \\
\hline
\end{tabular}

\begin{tabular}{|c|c|c|c|c|}
\hline \multirow{2}{*}{$\begin{array}{l}\text { Operative time } \\
\text { in minutes }\end{array}$} & \multicolumn{2}{|c|}{ Group A } & \multicolumn{2}{|c|}{ Group B } \\
\hline & No. of cases & \%age & No. of cases & \%age \\
\hline $5-10$ & 2 & 6.67 & 0 & 0 \\
\hline $11-15$ & 16 & 53.33 & 0 & 0 \\
\hline $16-20$ & 8 & 26.67 & 7 & 23.33 \\
\hline $21-25$ & 4 & 13.33 & 13 & 43.33 \\
\hline $26-30$ & 0 & 0 & 6 & 20 \\
\hline $31-35$ & 0 & 0 & 3 & 10 \\
\hline $36-40$ & 0 & 0 & 1 & 3.33 \\
\hline Total & 30 & 100 & 30 & 100 \\
\hline Range & \multicolumn{2}{|c|}{$8-22$} & \multicolumn{2}{|c|}{$16-36$} \\
\hline Mean $\pm S D$ & $15.30 \pm 3$ & & $24.20 \pm 5$ & \\
\hline 't' and $P$ value & \multicolumn{4}{|c|}{7.64 and $<0.0001$} \\
\hline Sig. & \multicolumn{4}{|c|}{ Highly significant } \\
\hline
\end{tabular}




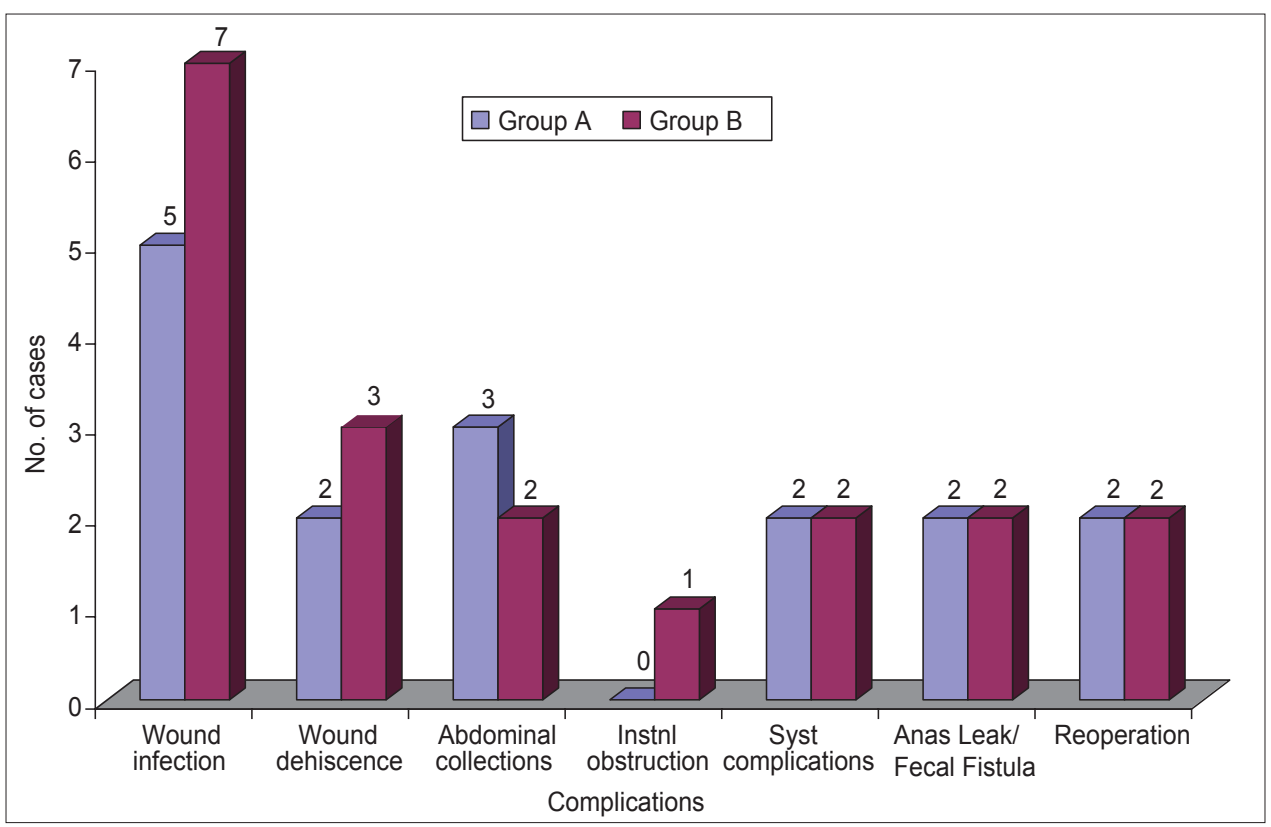

Figure 1: Complications in the study group

Numbers of anastomotic techniques are available but because all compromise healing, none can be considered perfect. The optimal method of intestinal anastomosis would:

- Promote primary healing by achieving accurate alignment of the divided bowel

- Cause minimal disruption of local vasculature

- Incorporate the minimum amount of foreign material

- Not implant malignant cells at the anastomosis

- Not enhance the risk of metachronous cancers. ${ }^{8}$

The present study evaluated the outcome of single layer versus double layer ileostomy closure in terms of operative and post operative outcome in each group. In our study, single layer ileostomy closure $(50 \%)$ and double layer ileostomy closure of ileostomy $(50 \%)$ were the surgical procedures performed in 60 patients, the average duration of ileostomy before closure was 101.75 days (3.39 month). The mean operation time for ileostomy closure from starting of first stitch to last stitch of anastomosis in single layer Group A was 15.3 minute ranging from 8-22 min and in double layer ileostomy closure Group B was $24.2 \mathrm{~min}$ ranging from 16-36 min. which was slight lower as compaired to study done by Burch et $\mathrm{al}^{9} 20.8 \mathrm{~min}$ for single layer and $30.7 \mathrm{~min}$ in double layer. And $26 \mathrm{~min}$ in single layer and $43 \mathrm{~min}$ for double layer studied by Ordorica et al. ${ }^{10}$ The average duration of hospital stay of the patients in Group I was 12.8 days and in Group II was 11.7 days which was in comparison to 10.4 days in both group by Ordorica et $\mathrm{a}^{10}$ and 11.4 days in single layer and 18.6 in double layer by Maurya et al. ${ }^{11}$
In our study complication occurring after stoma reversal was noted in both groups. In Group A wound infection was most common complication 5 (16.67\%) followed by abdominal collection $3(10.00 \%)$, wound dehiscence and systemic complication $2(6.67 \%)$ each. In Group B wound infection was most common complication 7 (23.33\%) followed by wound dehiscence $3(10.00 \%)$, abdominal collection and systemic complication $2(6.67 \%)$ each and intestinal obstruction in $1(3.33 \%)$. Anastomotic leak occur in $2(6.67 \%)$ patients in each Group in our study requiring reoperation. Various studies show comparison in single layer and double layer in tearms of leak. Irvin et a ${ }^{12}$ show leak in $5 / 29$ patients in single layer and $5 / 31$ in double layer. Six by forty leak in single layer and 13/52 in double layer shown by Everett et al, ${ }^{13}$ Golinger et al, ${ }^{14}$ Maurya et al, ${ }^{11}$ Ordorica et $\mathrm{al}^{10}$ and Burch et $\mathrm{al}^{9}$ show leak in single layer ileostomy closure $31 / 69,4 / 60,2 / 42,2 / 59$ respectively and $17 / 66,20 / 112,3 / 44,1 / 66$ respectively in double layer ileostomy closure.

The point against double layer are that it ignores the basic principle to accurately opposing the clean cut edges and large amount of ischemic tissue within the suture line which may increase the incidence of leak and excessive inversion may lead to narrowing of lumen. ${ }^{9}$ In contrast, single layer technique, employing extra mucosal sutures allows for accurate opposition, incorporate the strongest layer (submucosa) of gut, causes minimal damage to submucosal vascular plexus and least disturbance to lumen. ${ }^{15,16}$

Although various endpoints can be used to assess efficacy and safety of intestinal anastomosis, risk of leak after operation occupies the greatest attention among surgeons. Because 
there is no difference in the main outcome between two techniques in terms of complications in our study, choices in clinical practice should be made after taking into account the results of other outcomes such as mortality, duration of anastomosis procedure, duration of TPN, length of hospital stay, risk of wound infection, and cost of sutures. Arithmetical means of these endpoints suggests that the single-layer method offers almost the same or better results than the two-layer method. To conclude, two-layer anastomosis for ileostomy closure offers no definite advantage over single layer anastomosis in terms of postoperative leak and other complications. Single layer ileostomy closure technique is safe, easy to perform and simply to taught. Considering duration of the anastomosis procedure and medical expenses single-layer intestinal anastomosis may prove the choice of procedure for most of the surgeons.

\section{REFERENCES}

1. Gooszen AW, Geelkerken RH, Hermans J, Lagaay LB and Gooszwn HB; Quality of life with a temporary stoma: lleostomy vs. colostomy. Dis Colon Rectum 2000; 43(5):650-655

2. Khan N, Rahman A and Sadiq MD. Single layer interrupted serosubmucosal (extra mucosal) intestinal anastomosis $\mathrm{J}$ Med Sci 2006; 14(1):10-13.

3. Brooks DC and Zinner MJ. Surgery of Small and Large Bowel. In Maingot's Abdominal Operations, Volume 2. 10th edition. Edited by: Zinner MJ. Stamford: Appelton \& Lange; 1997; 1309-1310.

4. Cohen $Z$ and Sullivan B. Intestinal anastomosis. In: Wilmore DW, ACS Surgery, Principles and Practice. New York, WebMD. 2002; 803-805.
5. AhChong AK, Chiu KM, Law IC, Chu MK and Yip AW. Singlelayer continuous anastomosis in gastrointestinal surgery: $A$ prospective audit. Aust NZ J Surg 1996; 66: 34-36.

6. Sarin $S$ and Lightwood RG. Continuous single-layer gastrointestinal tract anastomosis: a prospective audit. $\mathrm{Br} \mathrm{J}$ Surg1989; 76:493- 495.

7. Orr NWN., A single layer intestinal anastomosis, Br J Surg 1969; 56:771-774.

8. Hamilton JE. Reappraisal of open intestinal anastomosis. Ann Surg 1967; 165:917-923.

9. Burch JM, Franciose RJ, Moore EE, Biffi $\mathrm{WL}$ and Offner PJ. Single layer continuous versus two layer interrupted intestinal anastomosis: A prospective randomizedtrial. Ann Surg 2000; 231: 832-837.

10. Ordorica-Flores RM, Bracho-Blanchet E, Nieto-Zermeno J, Reyes- Retana R, Tovilla-Mercado JM and Leon-Villanueva V. Intestinal anastomosis in children: A comparative study between two different techniques. J Pediatr Surg 1998; 33:1757-1759.

11. Maurya SD, Gupta HC, Tewari A, Khan SS and Sharma BD: Double layer versus single layer intestinal anastomosis: A clinical trial. Int Surg 1984; 69:339-340.

12. Irvin TT, Goligher JC and Johnston D. A randomized prospective clinical trial of single-layer and two-layer inverting intestinal anastomoses. Br J Surg 1973; 60:457-460.

13. Everett WG. A comparison of one layer and two layer techniques for colorectal anastomosis. Br J Surg 1975; 62:135-140.

14. Goligher JC, Lee PW, Simpkins KC and Lintott DJ. A controlled comparison one- and two-layer techniques of suture for high and low colorectal anastomoses. Br J Surg 1977, 64:609-614.

15. Subban A, Anis $N$ and Baloch AM., One layer interrupted intestinal anastomosis JCPSP 2001; 6 (2); 9-10.

16. Leslie $A$ and Steele RI. The interrupted serosubmucosal anastomosis-still the gold standard. Colorectal Dis 2003; (4): 362-366.

\section{Authors Contribution:}

Sushil Mittal, Harnam Singh- Substantial contributions to conception and design; Anand Munghate, Gurpreet singh, Manish YadavAcquisition of data, Analysis and interpretation of data, drafting the article; Anand Munghate, Anjna Garg- Revising it critically for important intellectual content; Sushil Mittal, Harnam Singh- Final approval of the version to be published.

Source of Support: Nil, Conflict of Interest: None declared. 